\title{
EMPIRICAL RESEARCH INTO THE PROBLEM OF OTHER MINDS: HOW DEVELOPMENTAL SOCIAL PSYCHOLOGY CAN STRENGTHEN THE WITTGENSTEINIAN ATTITUDINAL APPROACH ${ }^{1}$
}

\begin{abstract}
My goal in this paper is to examine the Wittgensteinian attitudinal approach to the problem of other minds initially proposed by M.R.M. ter Hark (1991) and developed by Hyslop (1995). As some other Wittgensteinian approaches this one also starts with the assumptions 1) that there is no asymmetry between self knowledge and knowledge of others and 2) that the relation between our inner states and outer behavior is a conceptual one. However, it differs from the standard Wittgensteinian approaches, mainly in its claim that knowledge of others does not come in the form of a belief that needs to be justified but rather in the form of an attitude toward others. This attitude is an intuition that enables us to form beliefs about other people. To explicate what this exactly means is my first goal in this paper. The second one is to examine how viable this position is. I plan to do this in an unorthodox way and ask psychologists to help me out. I argue that the insights we gain from developmental psychology can cast some light on how children develop a 'Wittgensteinian' intuitive attitude toward others. In the final section I turn to Hyslop's claim that even this approach which distances itself from beliefs and justification of beliefs cannot overcome skeptical worries. Hyslop goes on to argue that our intuitions may be strong but wrong as is the case with racist and sexist intuitions. My goal is to show that Hyslop's analogy between our attitude toward others and racist or sexist intuitions fails and that a naturalized attitudinal approach, the way I present it, stands further away from the skeptical attack than Hyslop has envisioned.
\end{abstract}

Key words: problem of other minds, attitudinal approach, skepticism, joint attention, development

Even though it might appear that the problem of other minds raises the question about the nature of our psychosocial strategies for making sense of other people, their thoughts, feelings, and actions, this is not its focal point.

1 Ovaj članak nastao je u okviru projekta"Dinamički sistemi u prirodi i društvu: filozofski i empirijski aspekti" (evidencioni broj 179041), koji finansira Ministarstvo prosvete, nauke i tehnološkog razvoja Republike Srbije. 
Philosophers have not typically been inquisitive about strategies that help us realize, for instance, that a friend of ours is depressed or how often we get it right when we speculate about what she thinks. The philosophical problem of other minds runs deeper than this. This problem is about how I know if there were other minds like mine at all and how I could justify such knowledge. In other words, it is not simply about how I can know what other people think but about how I can know if they think. This radical question that opens up an equally radical gap between others and me is what is considered to be the traditional philosophical problem of other minds. Formulated in this way the question of other minds appears to be a textbook example of an epistemological question: it is the question about the nature and justification of our knowledge. ${ }^{2}$ But, given its radical nature, we might ask how did philosophers end up questioning the existence of other minds on such fundamental level? Where and how does this problem occur?

The philosophical problem of other minds is often described as a problem that arises from the asymmetry between the way we get to know our own mental states and the way we get to know that other people have similar states. While it seems that we know ourselves directly, our knowledge of others (if we have such knowledge) is indirect. The problem is often traced back to Descartes' philosophy while a variety of solutions have been proposed since then. Two major opposing philosophical camps have emerged. On one hand, there are philosophers who do accept this asymmetry of knowledge. Their goal is to show that despite the fact that we cannot reach other people's minds directly we do have enough inductive evidence to know that they do have minds (see e.g. Mill 1872, Russell 1970, Hampshire 1970). On the other hand, philosophers working within the Wittgensteinian tradition (such as e.g. Malcolm 1958, Hacker 1972) tend to reject such asymmetry altogether arguing that the nature of our knowledge of other minds as well as the evidence we have for it is not based on empirical evidence at all. The crux of their argument is that the relationship between our minds and our behavior is not causal and contingent (i.e. empirical in any way) but conceptual. Thus, our knowledge of other people, their thoughts and feelings, depends on our knowledge of the meaning of mental concepts such as pain, joy and the like along with our estimate of whether people's behavior fulfils the criteria for being in pain or feeling happy. When these criteria are fulfilled there is no space left for any doubt about the existence of their minds.

My goal in this paper is to examine one version of the Wittgensteinian approach to the problem of other minds proposed by M.R.M. ter Hark (1991). Hyslop (1995) refers to it as the Wittgensteinian attitudinal approach while making cautionary note that this might not be the solution that Wittgenstein himself had in mind. Nevertheless, the approach is Wittgensteinian as it starts with the assumption that there is no asymmetry between self knowledge and knowledge of others as well as that the relation between our inner states and outer behavior is a

2 Whether the problem is merely epistemological or comes with the whole package of ontological assumptions has been debated on many occasions. For the review see e.g. Avramides (2001). 
conceptual one. However, it differs from the standard Wittgensteinian approaches, mainly in its claim that knowledge of others does not come in the form of belief that needs to be justified but rather in the form of the attitude toward others. This attitude is an intuition that enables us to form beliefs in the first place. To explicate what this exactly means is my first goal in this paper. The second one is to examine how viable this position is. I plan to do this in an unorthodox way and ask psychologists to help me out. I will argue that the insights we gain from developmental psychology can cast some light on how children develop a'Wittgensteinian' intuitive attitude toward others. In a nutshell this will be my attempt to naturalize the attitudinal approach to other minds. In the final section I will turn to Hyslop's claim that even this approach which distances itself from beliefs and justification of beliefs cannot overcome skeptical worries. Hyslop goes on to argue that our intuitions may be strong but wrong as is the case with racist and sexist intuitions. My goal is to show that Hyslop's analogy between our attitude toward others and racist or sexist intuitions that we might develop about them fails and that a naturalized attitudinal approach, the way I present it, stands further away from the skeptical attack than Hyslop has envisioned.

\section{The attitudinal approach}

A variety of Wittgensteinian solutions ${ }^{3}$ to the problem of other minds gained popularity among ordinary language philosophers of the twentieth century. In its traditional form a Wittgensteinian approach is meant to be the alternative to the analogical argument, and of course, unlike the analogical argument, to be successful in answering the skeptic. So, let me briefly summarize what the argument from analogy is all about. The argument is built on two main presuppositions: the first one is epistemological and is about two kinds of knowledge that we have while the second one is ontological and is about the nature of the relationship between our inner mental states and our outer behavior. So, let me take a closer look at both of these presuppositions.

According to J. S. Mill (1872), who was among first to explicitly formulate the analogical argument, there is an important distinction between two kinds of knowledge: knowledge that we get directly through consciousness (based on our intuitions) and knowledge that we get through inference. Knowledge about our own sensations comes to us directly while the knowledge about the outside world including our knowledge of other minds must be inferred. But, how do we make such inference about others? Mill argues that we initially notice the connection between our own sensations and behavior. Having done this we acknowledge that others behave in a similar fashion but that their behavior is not correlated with our own sensations. From here we conclude that their behavior must be connected to the sensations of their own. Now, Mill insists that the conclusion

3 There have been the old and the new Wittgensteinian arguments. The former has been proposed and defended by Norman Malcolm $(1958,1959)$. The latter has been defended by Saul Kripke (1982). As I am interested in the attitudinal approach proposed by M.R.M. ter Hark I will not be concerned with the differences between the other two. 
that we reach by analogy can be subsequently verified by further observations. Mill thought that the repeated ongoing experiences and observations make this inductive argument a good one.

At this point, we can ask what kind of implications Mill's epistemology has for the way we conceptualize the relation between our inner mental life and our behavior. We can find the answer to this question in Russell's version of the argument (1970). Russell argues that there is a causal relation between our inner mental states and outer behavior, a relation that we are able to observe directly. Based on this observation we infer that a similar connection obtains in other people. However, causal connection between my thoughts and feelings, on one hand, and my behavior on the other does not obtain every time even in my own case. Even if it did it would not be certain that it does apply to other people. Thus, Russell concludes that causal connection when it comes to others cannot be inferred with certainty. However, it can be inferred with high probability. To fight the skeptic high probability is all that we need, though. Or so Russell thought.

The argument from analogy faces some serious problems. One of the main worries with the argument is that our reasons for believing in other minds are based on the sample of one, i.e. on observations of ourselves. As we know, a single case is always a poor inductive base. Furthermore, we can use the main insights from the famous Wittgenstein's private language argument (1953) and conclude from it that it is not even clear how we can intuitively detect the relationship between our inner feelings and thoughts and outer behavior without publicly shared language. This language enables us to identify and categorize these inner feelings and thoughts in the first place. In other words, without publically shared language we would not be able to intuitively know ourselves and relate our inner life to outer behavior let alone apply this knowledge to the cases of others.

Some philosophers working in the Wittgensteinian tradition, such as Malcolm $(1958,1959)$ or Hacker (1972), have argued that the argument from analogy cannot possibly overcome these problems. So, instead of trying to fix it we should reconsider the two aforementioned presuppositions, epistemological as well as ontological, that the argument is built upon. This basically means that we need to propose a new way of understanding our self knowledge as well as the new way of conceptualizing the relationship between inner mental life and outer behavior. So, how are we going to do this?

While writing Philosophical Investigations (1953) Wittgenstein was occupied with the same worries. Even though there has been a lot of disagreement about the proper interpretation of what Wittgenstein really had in mind and what his position really was, most interpreters agree that he rejected the idea that we know our own mental states by introspection and that the relation between mental states and behavior is causal, thus rejecting both main presuppositions of the analogical argument ${ }^{4}$. Let me elaborate both of these points.

4 An introductory survey of different interpretations of Wittgenstein's take on language, mind, and conceptual versus empirical connection between inner and outer can be found in: Miller, Alexander and Crispin Wright, Rule-Following and Meaning (2002). However, I will focus on the standard interpretation offered by Malcolm $(1958,1959)$ and Hacker $(1972)$. 
According to Malcom and Hacker Wittgenstein denied that we have introspective knowledge about our inner states. This basically means that we do not observe our own thoughts and feelings with some inner, intellectual eye. Furthermore, we do not introspectively know, i.e. make the connection between inner mental states and outer behavior. Indeed we are aware of how we feel, what we think, and what we want to do. But, this self-awareness is not of an introspective kind; the kind that presupposes that we are spectators of our own mental life. Our awareness of how we feel or what we think does not constitute theoretical or intuitive knowledge. It is neither indirect nor direct. In the same time the relationship between our inner states and outer behavior is not external, causal, and contingent. Our outer behavior is internally related to how we feel and what we think and represents the expression of our inner life 5 . In other words, inner mental life and behavior are not two different entities in a causal relationship but rather two aspects of one phenomenon. I will say more about developmental origins of this internal link between inner mental life and outer behavior, but for now it is important to keep in mind that for Wittgenstein the crucial step in rethinking the problem of other minds is to redefine the way we understand selfknowledge and the way we conceptualize the inner/outer distinction.

Having abandoned the concept of introspective knowledge in our own case and contingent empirical relations between our inner lives and behavior we can proceed to apply these insights to the problem of other minds. So, assuming that there is an internal link between our inner feelings and our behavior, such a link needs to obtain in the case of other people as well. This means that, if such a link does obtain, when we observe other people's behavior we observe their mental states too. But, what exactly does it mean 'to observe the mental lives of others in their behavior' and how within Wittgensteinian position we can hope to avoid skeptical worries with this move?

As we have seen according the Wittgensteinian view the relationship between inner life and outer behavior is not empirical. The question is: if it is not empirical what is it? Malcolm and Hacker are going to argue that the nature of their relationship is conceptual. This means that our concept of behavior already involves the concept of inner pains, joys, beliefs, desires and the like. We can make an artificial distinction between the two (inner and outer) and think of them as separate events or phenomena but 'scream' and 'pain' come together conceptually. In our own case screaming is the expression of pain. In the case of others their screaming meets the criteria by which we determine that they are in pain. More precisely, this means that when we observe other people we judge whether their behavior passes the criteria for what e.g. being in pain or being happy is. This is what it means to observe pain in pain behavior. We do not conclude or infer from scream that somebody is in pain. We see that they are in pain as we know what pain means and that meaning involves a particular kind of behavior.

Now, this has important implication for the skeptical worries about other minds. In the standard Wittgenstenian approach when somebody passes the

5 Even though Malcolm and Hacker portray Wittgenstein as holding firmly to this view there are some indications pointed by L. Kojen (2009) that Wittgenstein himself had doubts that all mental terms and their meanings could be identified and reduced to one function: our expression of the inner mental life. 
criteria for being in pain this serves as justification of our belief that they are indeed in pain. However, this justification does not come from inductive inference nor does it consist of gathering empirical evidence of any sort as the relation between inner states and outer behavior is not causal but conceptual. So, there is no need to worry about the inductive base that is too small nor about the way we make intuitive connection between inner and outer (or the way we generalize such knowledge to others) as we do not make such connection at all. We know what other people feel because we know the meaning of the words and since we know the meaning of the words we see their pain in their behavior. Thus, when other people pass the criteria for being in pain then we can conclude that they are indeed in pain without worrying about skeptical objections.

The Wittgensteinian approach I presented here is what is usually called the criterial approach to other minds. Now, let me turn and see how it differs from the other version of the Wittgensteinian approach, namely the attitudinal approach. My plan is to clarify and defend the latter in the following sections. While the criterial and the attitudinal approach share the assumptions related to the inner/outer connection and the nature of self-knowledge the major difference between the two lies in the way they conceptualize our knowledge of others. What they have on common is as follows: a) the relationship between our inner states and outer behavior is not external, causal, and contingent; b) our awareness of how we feel or what we think does not constitute theoretical or intuitive knowledge. It is neither indirect nor direct. However, within the criterial approach our knowledge of others comes in the form of beliefs while in the attitudinal approach the knowledge of others is not a set of beliefs at all ${ }^{6}$.

Given that the crietrial approach presupposes that we do indeed have beliefs about other people's minds (e.g. that somebody is in pain, or is happy, or believes in gender equality) the question that the skeptic asks is whether we can justify such beliefs? According to the criterial approach this justification does not come from induction as the relation between inner life and behavior is not empirical. However, justification does not and cannot come in the form of logical entailment either as the relationship between the two is not strictly speaking logical. If the connection were logical the inner feelings would entail outer manifestations. We are all aware that this is not the case. People are able to hide or fake their pains. There is no logical entailment between the two. As Hyslop correctly points out, the standard criterial approach is meant to find a 'midway between entailment and induction' to justify our knowledge of other minds. In a nutshell, the goal of the criterial approach is to defend our knowledge about other minds within the framework of standard folk psychology ${ }^{7}$. This basically means that such approach presupposes that our knowledge of others comes in the form of beliefs.

6 As we will shortly see when I turn the developmental issues (development of mind, social cognition, language) these two approaches are not necessarily mutually exclusive. However, the research in developmental psychology indicates that the attitudinal approach to other minds develops first and serves as the basis for language development within which the cirterial approach to other minds makes sense.

$7 \quad$ 'Folk psychology' is the term used in many different ways in cognitive science and philosophy of mind (for the review see e.g. Clarke 2001). However, when philosophers and cognitive scientists talk about folk psychology they usually presuppose that folk psychology must 
Now, if it comes in such form then it needs some sort of justification if it is to avoid skeptical worries.

To summarize, according to many classical interpretations of Wittgenstein (such as Malcolm's and Hacker's) Wittgenstein did argue for the conceptual (not empirical) link between inner mental states and outer behavior while he still seemed to be endorsing the view that our knowledge of others comes in the form of beliefs and that our beliefs about other people mental states need to be justified. According to these interpreters, we justify such beliefs through examining the conceptual criteria for being in a certain mental state and whether the person in question fulfils such criteria. When a person fulfils the criteria for a particular mental state we are justified in believing that they are indeed in such state. Malcolm's famous example of scratching and itching nicely illustrates this point (Malcolm 1959). We know that itching and scratching are related. Within the criterial approach their relation is conceptual. So, when somebody is scratching we know they are itching. This is not inductive or logical truth but conceptual. Scratching fulfills the criteria for itching and we can justify our belief that whoever is scratching that they are itching as well.

As Hyslop points out, this standard criterial approach faces a serious problem: if the relationship between inner and outer is not the one of logical entailment how could criterial justification provide certainty, (certainty that would satisfy the skeptic) for our belief that other minds exist? Furthermore, given the possibility of pretending and lying many would agree that psychobehavioural relations are a bit further from logical entailment and closer to empirical contingency. To try to be in between and say that their relationship is not empirical but of conceptual/ logical nature of a particular kind that does not involve logical entailment remains unclear ${ }^{8}$.

Now, the question is can we find the way out of these worries but not fall back to the already abandoned analogical arguments? It seems that there is still one possible exit for those inclined to accept Wittgensteinian strategy but it is the radical one. Namely, one possible solution is to argue that our knowledge that other minds exist does not come in the form of belief at all and hence there is no need to justify it. This requires some further unpacking.

First, if we banish the concept of knowledge, at least the concept of knowledge that comes in the form of propositional attitudes (beliefs), when it comes to mental states (either ours or that of others) the question is how we are to think about the fact that we indeed seem to know how we feel and seem to know (through observation) how other people feel. Hyslop tries to answer this

include human ability to form beliefs about beliefs of others, i.e. it must involve human ability to ascribe beliefs to others in order to explain and predict their behavior.

8 I am grateful to the reviewer of this paper for the suggestion that the fulfillment of the criteria could be 'ceteris paribus' or defeasible by other factors (such as the context). This would give us something less than entailment but such fulfillment of the criteria would be categorically different from induction. However, no matter how we clarify the status of the conceptual justification it seems that the skeptical worry will not go away unless we have the certainty of logical entailment. So, the question would still remain: can we overcome this worry and win against the skeptic even if we successfully defend the independent status of conceptual justification? 
by saying that: „Something perhaps deeper than knowledge applies in one's own case, something prelinguistic even." (1995, p. 124). As for other people and their minds Hyslop says that our knowledge of them is rather a form of an attitude (also probably paralinguistic) that already involves treating others as minds never as mere bodies. When Hyslop insists that we are aware of ourselves on a deeper, prelinguistic level and that we have the approach to others that already presupposes their minds he wants to differentiate linguistic knowledge that usually comes in the form of propositions, propositional attitudes, shortly in the form of beliefs from immediacy of self-awareness and our strong intuition that other people indeed think and feel. The latter point is in a sense a step beyond the Wittgensteinian point that inner life is conceptually related to outer behavior. We should think of it as a prelinguistic intuition which tells us that others are persons with their thoughts, feelings, and intentions. So, when we say that we see mind in other people's behavior this 'seeing' of the mind is happening on the basic perceptual level and does not come out from some semantic knowledge of the meaning of the words. It would follow then that the mental concepts and their meanings as well as Wittgensteinian thesis that the relations between behavior and inner life is conceptual have their roots in something more basic. In other words, the attitudinal approach presupposes something stronger then conceptual relation between inner and outer as it has roots in prelinguistic not linguistic practices. Moreover, as we will see shortly these prelinguistic practices are developmental prerequisite for normal language development. This means that the conceptual relation between inner and outer emerges from paralinguistic practices that we are engaged in. In the next section I will say more about this.

When we think about the phenomenology of our everyday experience it seems that there is nothing problematic so far about the main theses of the attitudinal approach. When we see someone fall down there is this immediacy of being aware that they are in pain (even though we do not feel it) in the same way there is the immediacy of feeling our own pain. There seems to be no in between steps of introspection or inference in any of these cases. This immediacy allows us to be certain about ourselves and others. According to the attitudinal approach, this certainty does not come in the form of justified belief or belief at all. But, the question still lingers: what is this attitudinal approach exactly and how does such attitude give us such certainty? In the following section I will examine whether we can clarify what this exactly means, what the attitudinal approach involves, and what it implies. In order to do this I am going to use some findings and insights that are coming from developmental science.

\section{Development of social cognition: some insights from psychology}

Many philosophers involved in this discussion will find counter intuitive the attitudinal approach described in the previous section. The main reason for being wary of such an approach is because it seems somewhat uncontroversial that our knowledge of other minds does indeed involve all sorts of beliefs and 
that we have good or not so good reasons for holding such beliefs. To argue that our knowledge of others does not even come in the form of beliefs seems strange. Even if at the first glance such position appears to be promising in the fight against skeptical worries it still seems to be raising more questions than it promises to solve.

What is this attitude after all? What is its nature and how are we to think about it? So far we only know what this attitude is not: it is not a belief and it should be psychologically and epistemologically deeper than belief. It is supposed to allow us to have the immediacy of knowing that others are in pain without us having to do any inferring. However, in many cases it does seem that we are engaged in a reasoning process trying to figure out how people really feel and what they think. We use all sorts of strategies and all kinds of evidence to come to the conclusion about their inner states. This kind of reasoning seems to suggest that our knowledge of others does indeed come in the form of belief and requires justification. The required justification could be only obtained through induction or logical entailment. This brings us back to the dilemmas and problems that both criterial and analogical approaches have faced.

Indeed, this brief and very general analysis of our everyday musings about other people's inner lives does not necessarily imply that we need to give up the attitudinal approach altogether. However, in order to hold on to it we need to specify more closely what exactly this attitudinal approach is. Furthermore, in order to convince anybody to embrace such an approach we need to explain why it seems that we do form beliefs about other people's minds and why we do search for evidence for the beliefs we have formed. That is, we need to show how our everyday practices of forming and justifying beliefs emerge from the attitudinal, prelinguistic knowledge.

In order to do this we need to step back from our everyday practices and look at how such practices develop. More specifically, we need to take a look at the development of social cognition. This is not something philosophers like to do but it is nonetheless of crucial importance for this particular problem. In the rest of this section I will try to outline the origins of this prelinguistic attitude toward others as well as to show how our beliefs about others emerge from prelinguistic knowledge that children develop throughout the first years of life. I hope that this developmental journey will clarify in what way such specific attitude toward others represents the foundation for more sophisticated linguistic forms of social cognition.

Let us first see at what age children begin to understand that other people have beliefs of their own and how people form such beliefs. Back in 1983 Heinz Wimmer and Josef Perner developed a test that was meant to answer these questions. This test is now known as false beliefs test. In the test children are presented with the following story: Maxi places some chocolate in a cupboard in the kitchen and leaves the room. While Maxi is away, another character takes the chocolate from the first cupboard and puts it in the second cupboard, and then leaves. When Maxi returns, the child is asked to predict where Maxi will look for the chocolate. The correct answer, of course, is that Maxi will look for the 
chocolate in the first cupboard because we know that Maxi could not know that the chocolate was moved to another drawer. This experiment has shown that children of four years and older do understand what Maxi can and cannot know about this situation. Younger children do not have this understanding as yet and cannot answer the questions about Maxi's beliefs properly. Instead they tend to apply what they know, i.e. their own beliefs, to Maxi.

However, even before children develop the ability to correctly attribute beliefs to others they do engage in social interaction and show basic ability to interpret other peoples' intentions. It is not surprising that such ability starts very early, during the first year of child's life, even before language kicks in. I will trace back and outline these prelinguistic origins of social cognition in the attempt to show how this prelinguistic attitude toward others as intentional beings (rather than mere objects) emerges. As we will see shortly the development of social cognition in infants is the single most important predictor of successful language acquisition. In the case that this development is derailed the language development is derailed too. The case of children with autism illustrates well the connection between prelinguistic social cognition and language development. I will come back to this to this point at the end of this section.

The world in which the child is born is intrinsically social as the child needs a caregiver if she is to survive. The caregiver needs to be there for the child not only to feed her but to regulate her arousal states so that the child gets enough sleep as well as enough external stimuli that are necessary for normal physical and psychological development (see e.g. Shanker 2013). The child at birth does not have the required regulatory systems in place so the caregiver serves as a sort of the external regulating brain (Tantam 2009) to a child. If the child is to be successful and develop quickly the child needs to be able to tune in and read social cues coming from the caregiver. The better the child is in this non verbal communication the better the development of her self-regulatory, cognitive, affective systems will be. So, the first precursors of nonverbal communication start at birth.

However, the most important step in development of such communication is marked by the emergence of joint attention when the child is approximately nine months old. Joint attention refers to the ability to "coordinate attention between interactive social partners with respect to objects or events in order to share awareness of the objects and events" (Mundy et al. 1986, p. 657). It is important to note that the child who is able to engage in joint attention is able to make use of the caregiver's communicative signals. In other words, through preverbal communicative signals, the child and the caregiver are able to follow and direct each other's attention. The clear sign that the child is able to make use of the communicative signals of a caregiver can be seen in her ability to follow the gaze of the caregiver and determine the object(s) to which the caregiver intends her to attend.

It is very likely that the nature and the development of these preverbal signals highly depend on the child's tendency to attend to and make sense of the caregiver's emotional expressions. For one thing, being preverbal, these 
signals consist of expressions of approval, disapproval, surprise, and the like (i.e., they, at least partially, consist of emotional expressions). That is, along with the more conventional communicative gestures, such as pointing ${ }^{9}$, emotional expressions can efficiently direct the attention of a communicative partner to a particular object or a property of an object in the joint attentional scene. For another thing, joint attention episodes are frequently punctuated and motivated by affective engagement with another (Paparella, D’Angiola, \& Kasari 2001; Paparella \& Kasari 2002).

Joint attention as described here is apparently one of the crucial steps in understanding other people's minds. The child is not as yet able to comprehend entirely what it means to have inner mental life and what exactly beliefs are (nor is she able to differentiate her own beliefs from that of her mother) but is nonetheless able to understand that other people want them to pay attention to an object or want them to do something (or to stop doing something). Children also become increasingly aware of their own agency, i.e. that they, themselves, can also direct other people's attention and make them do what they want. This is all happening prior to language acquisition while communication is taking place in the medium of gestures and emotional expressions. For the child the expression on mother's face is the emotion that mother feels and that emotion tells the child how to proceed and what to do. The child is also able to direct mother's actions by using her own gestures and expressions. There is immediacy in these co-regulated activities. Here we can find the origins of treating other people as minds not as mere objects. Even before the child is able to engage in joint attention the child does differentiate between inanimate and animate objects (for review see Johnson 2000). With joint attention the child begins to understand that other people have intentions. But the concept of belief and what it means to have a belief and how these beliefs are formed is yet to be acquired. The acquisition of such concept requires language ${ }^{10}$.

Now, the studies of children with autism have repeatedly shown that there is a close connection between language acquisition and participation in the joint attentional scenes. It is well known that the participation in joint attentional scenes emerges (if at all) very late in the development of children with autism (Charman 2003; Kasari, Sigman, Mundi, \& Yirmiya 1990; Leekam, Lopez, \& Moore 2000; Loveland \& Landry 1986; Mundy \& Crowson 1997). Considerable

9 Given that the emergence of social orienting and attention to distress occurs long before the child acquires conventional communicative gestures, it would be worthwhile to explore how the former relate to the latter and whether the origins of communicative gestures lie in the more basic understanding of emotional expressions.

10 It is not surprising that language acquisition is a crucial factor in category development, concept acquisition, and the development of abstract thought. It has been shown that language acquisition shapes the development of concept acquisition and category formation (see. e.g. Markman 1989), and contributes in an important way to flexibility in categorization tasks (see e.g. Ellis \& Oakes 2006). In other words, once language kicks in, along with the child's ability to communicate linguistically, language is the main medium of social learning and, as such, is the driving force behind category development and concept acquisition which includes the acquisition of mental concepts such as pain and happiness and more abstract mental concepts such as beliefs and desires. 
delay in joint attention is followed by the delay of language acquisition and the further impaired development of social cognition in these children. So, in a way the prelinguistic understanding of others as minds with their own intentions is the foundations of language acquisition and as such represents the single key to the development of abstract thought that allows us to think about our own and other people's beliefs.

We can now pose a further question and ask what the origins of joint attention are. In the literature, there are two general ways of explaining normal development of joint attention. According to one approach, joint attention in normally developing children is explained by emotional interaction with their caregivers. As a result of normal emotional interaction they develop normal intersubjective relations (Hobson 1993) and engage in normal socio-emotional development (Mundy 1995). According to this approach, children with normal socio-emotional development exhibit normal face-to-face gaze, direction of attention, and appropriate patterning of behavior within interactions. All of the above enables them to participate in joint attentional scenes. According to the other approach, the origin of joint attention is primarily cognitive. Instead of looking into socio-emotional development, the proponents of this view hold that children develop their understanding of the caregiver's attention to an object. More precisely, children develop the ability to represent the relation between caregiver and the object to which the caregiver is attending (Baron-Cohen 1995; Baron-Cohen, Leslie, \& Frith 1985).

However, stated in the most general terms, the two approaches provide only a starting point for further research. Both views, if they are to be useful, need further refinement. The goal of the subsequent research is to determine, for example, in what way socio-emotional development brings about joint attention and/or what underlying mechanisms enable the child to develop proper understanding of the caregiver's attention.

It is not surprising that the main goal of the recent, more refined theories of the origins of joint attention is to identify the mechanisms responsible for, and the early precursors of the development of joint attention. Nor is it surprising that these theories do not pose the question of whether the impairment in joint attention is essentially affective or cognitive. Once we start identifying the underlying mechanisms for development of joint attention it appears that such development has links to all three areas of development: affective, cognitive, and sensory development.

In the more recent theories, then, a common strategy for explaining the origins of joint attention is to identify its precursors and explain how they emerge in development. For instance, social orienting is usually taken to be one of the main precursors of joint attention (for a comprehensive review, see Dawson et al. 2004). Social orienting refers to children's ability to „spontaneously orient to naturally occurring social stimuli in their environment" (Dawson et al. 2004, p. 272). Usually, children who have difficulties with social orienting, such as children with autism, also have difficulties with joint attention (Mundy $\&$ Neal 2001). Thus, it has been argued that if the child fails to orient to social 
stimuli, that is, if she fails to show appropriate attraction to people, particularly to the sounds and features of their faces, this will necessarily impair her ability to engage in joint attentional scenes (Dawson, Meltzoff, Osterling, Rinaldi \& Brown 1998; Mundy \& Neal, 2001).

The next question is what underlies the child's ability to orient to social stimuli successfully. Here, several theories have been proposed. In some instances, the social orienting is treated as a special case of a more general attentional functioning (e.g. Bryson, Wainwright-Sharp, \& Smith 1990; Courchesne et al. 1994; Dawson \& Lewy 1989a, 1989b). There are disagreements about the exact nature of this special case. According to Courchesne, Chisum, and Townsend (1995), early social exchanges are quite demanding and require rapid attentional shifts between different stimuli. In their view, this is exactly what children need to be able to do if they are to orient spontaneously to social stimuli. Others argue that the ability to shift attention is not of crucial importance; rather, the very nature of social stimuli is very complex and requires parallel processing (i.e. the processing of facial expression, speech, gestures, and the like at the same time). All of the above seems to be impaired in children with autism. One way to explain normal processing abilities is by turning to the proper connectivity of the brain regions. If such connectivity fails to develop the result might be impaired social orienting, joint attention, language acquisition or in a nutshell the result could be the onset of autistic spectrum disorder (Just, Cherkassky, Keller, \& Minshew 2004). Furthermore, there are authors who argue that children need to have a motivational neurological mechanism that assigns a reward value to social contact if they are to be drawn to social stimuli at all (Mundy 1995; Panskepp 1987). They also argue that this is exactly what children with autism do not have.

It is important to notice that these theories are not mutually exclusive. It might turn out that the connectivity of brain regions which enables normal processing as well as a reward mechanism are in play and jointly contribute to the normal development of social orienting and the processing of emotional expressions, which together lead to joint attention in children.

Recent studies have shown that typically-developing children first come to recognize emotional expressions by relying on intersensory perceptions. Later, they are able to focus on voice or facial expression and to extract emotional meaning from them alone (Walker-Andrews 1997). What this means is that the ability to recognize certain expressions depends on the proper integration of stimuli coming through vision, sound, and touch. Consequently, if the sensory channels do not work properly, the child will not be able to recognize emotional expressions, which will thus compromise her ability to grasp the emotional meanings of these expressions. This also might compromise the development of the neuro-affective motivation system (reward system) which, in turn, will compromise the child's interest in engaging in social interaction, thereby further derailing her social development. Of course, the causal chain can go in the opposite direction: it might turn out that the neuro-affective motivation system in the brain allows the child to enter social interactions, leading to normal brain development and the connectivity of brain regions. It is important to determine what exactly this causal chain looks like, and further research in this area would be invaluable. 
However, even the empirical findings collected so far point to a very interesting fact, namely that the child begins to understand emotional expressions and what they mean far before the child learns language. So, here is the first conclusion we can make that might contribute to better understanding of the Wittgensteinian attitudinal approach. It seems that in the first year of a child's life we can find the foundation for what is going to become the conceptual link between inner mental life and outer behavior that some Wittgensteinians have been looking for. More specifically, empirical findings have shown that if the child is to engage in joint attentional scenes the child needs to be able to decipher what it means when mom smiles or when she frowns. Furthermore, if the child is to learn language she needs to participate in joint attentional scenes. Given that the whole of language acquisition depends on this preverbal emotional communication we are safe to assume that the acquisition of mental concepts, the acquisition of the meanings of such concepts is in fact closely tied to these prelinguistic, nonverbal exchanges. When the child starts using mental concepts, such as „It hurts' or 'I am happy', the child starts using them in order to express what she feels. Once language kicks in the child will not rely on preverbal signals (only) to let others know how she feels. Moreover, we have seen that in preverbal communication mom's smile is her happiness while her frown is disapproval. This is what the child immediately knows and responds to before she learns language. So, when the child learns mental concepts this internal connection between smile and joy, or frown and disapproval is kept. Wittgenstein called this internal connection conceptual. We can now see that its origins lie in preverbal communication.

Finally, when children develop language they develop the ability to think about what they think and feel. With language they also develop the ability and the need to make sense of why we think and feel the way we do. This applies to their own case as well as the case of others. So, by the time they are four, children begin to understand what you need to see in order to form a particular belief and as a result they can pass the false belief test. With language development they also become aware that there are cases when people lie and start to search for the indicators that they are (not) lying or pretending in a particular case. In other words, they start to search for the evidence that their beliefs about other people's mental states are correct. But, it is important to notice that this comes much later when language and abstract capacities are fairly developed. It is also important to remember that these abilities grow out of immediacy of preverbal communication where possibility of lying and faking is yet to emerge. It is interesting to note that Wittgenstein in his Philosophical Investigations convincingly expressed similar view: „249. Are we perhaps over-hasty in our assumption that the smile of an unweaned infant is not a pretence?-And on what experience is our assumption based? (Lying is a language-game that needs to be learned like any other one.)" (Wittgenstein, Philosophical Investigations, p. 90).

All of the aforementioned insights are of crucial importance for understanding both the developmental origins of the attitudinal approach as well as how we become perplexed with the questions what other people feel and whether they really feel what we think they do. But this worry that others might lie or pretend does not arise prior to language acquisition nor are we worried 
about it in most of our encounters with other people. Even when we start suspecting that somebody is lying we deal with this particular case separately from the ordinary cases when we clearly see in other people's faces or hear in their words how they feel. The ordinary cases are in a sense a normal background for thinking about others. As Hyslop correctly notices, to wonder if somebody is lying or pretending is not the same as questioning that they are persons at all.

However, if we are philosophers it seems to us that we can radicalize and generalize these exemptions: namely, it seems to us that we can imagine not only that all people are lying or pretending all the time but also that they don't have any feelings and thoughts whatsoever. In other words, it seems to us that we can conceive of a situation in which other people behave exactly the way we do but that they have no feelings or thoughts inside at all: i.e. that they are nothing but machines. Once we radicalize problem in this way we start searching for some absolute and secure evidence for the existence of other minds. Let me phrase this in developmental terms. Even though the minds of others seemed to be fairly unproblematic to a child before she learns language once she learns language she is equipped to ask all sorts of questions about them including the very skeptical ones. But, this very possibility tells us more about the nature of our language than about the nature of other minds. That is, our language is such that we can make all sorts of distinctions and abstractions the way it suits us. We can categorize things in many ways and we can also change the rules of categorization as we go. We can make all sorts of arbitrary distinctions if they are useful in specific contexts or we can make them just for the fun of it. This is a precious feature of our language that allows us to investigate nature, be flexible, adapt well, predict the future, and think about the past. However, it also allows us to make distinctions such as the one between the inner mental life and the outer behavior. However, when we take a look at a child's development the first thing we notice is that there is no trace of such distinction in our developmental trajectory. On the contrary, everything that the child does before she learns language and long after she learns language goes against the assumption that such distinction makes sense at all.

However, even if this developmental story, that I've just told, is sufficiently convincing to make us embrace the internal, conceptual link between our inner feelings and behavioral expressions of these feelings there is still one more question we need to tackle. That is, we still need to see if the Wittgensteinian attitudinal approach backed with the developmental psychology is sufficient to dissolve skeptical worries. Let me, now, turn to this question.

\section{So far so good but can we deal with the skeptic?}

In the previous section I have argued for the psychological primacy of the Wittgenstenian attitudinal approach toward other minds. This primacy emerges in the first year of life and enables children to feel with and communicate well with their caregivers. Through these activities children develop understanding of others as intentional beings. This is very important finding as it seems that 
children even before they learn language, always treat their caregivers and peers as bodies with minds never as mere bodies. Furthermore, in the previous section I have also tried to outline how language and concept acquisition emerge from this attitude toward others. However, we can now ask if this psychological primacy is sufficient for the successful fight against philosophical skeptic. Hyslop thinks that it is not. So, let's go over his worries first and see whether he has a point.

The first question to ask is where the certainty in the existence of other people's minds (within the attitudinal approach) comes from. Hyslop argues that our certainty comes from the fact that we already think of other people's behavior as expressing sensation. „We view the behaviour, regard it, apprehend it, understand it, conceptualize it, see it, as expressive of sensation. That is, supposedly, why we are certain." (Hyslop 1995, p.128) As Hyslop goes on to argue this is probably our normal psychological response to other people. However, the problem arises when we start invoking regular psychological processes, mechanisms, and attitudes in order to justify our certainty. Indeed, identified psychological processes do explain why we feel certain that other people have minds but they do not justify such certainty. In other words, no matter how certain we might be about something this still does not mean that that something is really the case.

Hyslop uses several examples to illustrate how our psychological certainty can lead us astray. The cases of sexism and racism first come to mind. We all know that in the patriarchal society women are considered to be inferior. However, this attitude toward women does not remain on the level of beliefs and thoughts. It runs deeper. Women are, in fact, perceived as inferior. The inferiority appears on the observational level. What this means is that when a man sees a woman there is no need for him to infer that she is inferior. He perceives her like that. A man does not need to go and look for the inductive nor deductive evidence (he could if he was challenged to do so). Sexism is very often entrenched in the way people see the world not just the way they think about the world. The same applies to racism.

What is striking is that sexists or racists do seem to be certain about their conception of women or other races and they seem to have the attitude toward women or other races that is deeper than a theory or a system of beliefs. „For them the conception is simply of reality. It is completely on a par with seeing a painting as a painting. It is immediate. It is there, right in front of them, perceived as such." (Hyslop 1995, p. 129). Hyslop goes on to illustrate the similarities between the attitudinal approach to other minds and these other conceptions that people might develop:

It is not that those with the conception that, say, women's bodies are for the delectation of men, are other than misleadingly said to believe this. If they are thought to believe this the belief will be thought to arise from the conception. The conception is prior to, and deeper than belief. There is no gap in the conception, between outer and inner. A woman's body is seen as for the delectation of men, that is how they are perceived. That is the immediate experience, as immediate as in the case of the painting. (Hyslop 1995, p. 129) 
To summarize, the aforementioned cases of sexists and racists show that people can have a particular attitude toward others and that they could develop particular conceptions about them that are immediate and deeper than mere beliefs. Such conceptions appear as if they do not leave the space for error. However, they do. All of the above cases show that even very deep conceptions might be entirely wrong with no connection to reality. Thus, we can conclude that these conceptions do provide the feeling of certainty, but they do not justify such certainty. Hyslop argues that skeptic might say that similar conclusions apply to our attitude toward other people's minds. Even though we do have conceptions about their minds that are deeper than beliefs and that we do indeed perceive their minds in their behavior skeptic could argue that all of our conceptions about other people might be entirely wrong. After all: „That women are inferior is questionable, and questioned, and false. That blacks are inferior is questionable, and questioned, and false". (Hyslop 1995, p. 130) Why not assume that something similar could be the case when it comes to our conception of other minds? Now, let us examine if the analogy holds the way Hyslop seems to think.

On the structural level it seems that the similarity between the case of other minds (and our trust in other minds), the case of sexism, and the case of racism obtains. In all cases we perceive the mind (in the former case) or the inferiority (in the latter cases) on the very observational level. The very conception of other people involves minds. For sexists and racists the very conception of women and/or other races already involves inferiority. But, to look at these cases only on the structural level is not the only way we can compare them. I will argue that when we look at the developmental roots of our conception of other people (as having minds) we can see that the analogy between the case of other minds and the cases of sexism and racism breaks downs. Now, this is not to say that we will be safe from skeptical worries altogether. But, at least the skeptical attack will be postponed a bit and from this new developmental perspective will look less convincing.

The first thing that Hyslop has not taken into account is that our attitude toward other people as individuals with minds has developmental priority over any sort of sexism or racism. If a child and later the adult have trouble 'reading' other people minds it is hard to see how the child (or the adult) could be taught to see others as inferior. To be superior or inferior are social categories that are built upon the tacit assumption that others exist and have minds, i.e. that they have some capacity to think and feel.

But there is something more about the primacy of this attitude toward others that differentiates it from any other attitudes toward others (such as sexism and racism) that we might develop later. Some empirical findings coming from the research on autism indicate that the emergence of social cognition marks the emergence of mind, i.e. the emergence of our inner mental life and self consciousness.

As we have seen children with autism have problems in many areas of social cognition. They have problems with social orienting and joint attentional scenes. Their language acquisition is lagging behind and even when they do learn language 
their language remains rigid, their concepts and categories are inflexible (see e.g. Plaisted 2000, 2001) and their ability to read other people's minds remains poor. However, less known but very interesting finding is that inner life along with self consciousness in these children seems to be impoverished too. Or, as Currathers (1996) put it, children and individuals with autism do not only have impaired ability to ascribe beliefs and desires to others but also lack the ability to ascribe beliefs and desires to themselves. This means that their mind-blindness goes hand in hand with their lack of self knowledge. Baron-Cohen (1989) found that autistic subjects find it difficult to remember their own recent false beliefs. They also seem to have trouble drawing the appearance-reality distinction. If they don't have the concept of belief and desire, i.e. if they do not understand that it is one thing believing that something is the case and yet another that something is the case they would certainly have difficulty understanding the difference between their experience and what that experience is of (the reality). Similarly, Hurlbert et al (1994) found that individuals with Asperger syndrome find it hard to report their inner experiences. Even those who could pass advanced false belief tests did not report any inner verbalisation, unsymbolised thinking and emotional feelings. They only reported visual images. The ones who could not pass advanced false belief tests did not report any inner experiences at all. These are indeed striking findings as they indicate that impaired social cognition seems to be related to impaired self-awareness and impoverished inner mental life. This means that social cognition and inner mental life are both being constituted simultaneously through social interaction and preverbal communication during the first year of child's life.

The aforementioned cases of children with autism yet again illustrate the psychological primacy of our attitude toward others over any other conceptions about others that we might adopt later. It is in fact so important for normal development that children without it lack a diverse mental life and have substantially impaired self knowledge. Now, if the child is normally developing it will remain open and will depend on her immediate surroundings if she is going to become sexist or racist or liberal minded. But in order to become any of that she will need to develop the right attitude toward others, the one that will allow her to treat them as intentional beings with their own minds first.

There is another point that needs to be made here. The findings that indicate that our own mind is being constituted along with our knowledge of other people's mind is one of the single most important insights of developmental psychology. The sceptical worry about other people's minds starts off with the assumption that our own mind along with our self-knowledge comes first while our knowledge of others is somehow derivative and comes later. However, developmental psychology is telling us that developmentally this is not the case. The studies on autism have shown that there is no mind of ours or self-knowledge without knowledge of other minds and that they are being constituted simultaneously in the first year of child's life. Thus, it seems that there is no impairment in social cognition without the profound impairment in self awareness and affective development. The question now is whether these findings and the above points could satisfy our philosophical sceptic. 
I have shown that we could answer Hyslop's worries that the attitudinal approach is similar to sexism or racism in a sense that it gives us the feeling of certainty but that it may as well be unfounded as the other two. I have pointed out that there is developmental disanalogy (if not structural disanalogy) between attitudinal approach to other people's minds, on one hand, and sexism and racism, on the other. This means that if they are at least developmentally different and if the attitudinal approach has the primacy over other two we don't have to worry about that it might turn out that we are wrong about other people's minds in the same way as many have been shown to be wrong about inferiority of women or other races. Furthermore, I have argued that in developmental terms there is no asymmetry between our own mind and self-knowledge on one hand and other people's minds and our knowledge of their minds, on the other. As developmental science has shown both kinds of knowledge emerge in the same time. But, is this developmental dispersal of asymmetry sufficient to fight the sceptic? The answer must be no. However, some conditions apply. So, let me conclude with some thoughts about the nature of the sceptical endeavour.

As we have seen in the previous section our language is such that it enables us to abstract from many situations as well as to imagine and conceive of many novel ones. So, to all of the above findings from psychology the skeptic might say that they are of no help because we can still imagine situation in which all people around us are just robots. We can imagine that such robots have raised us and that we have passed though all of the necessary stages of normal psychological development which includes the development of our proper attitude toward others as fellow human beings and persons. But, in this imagined situation this attitude would be misleading as these others would have no inner mental life whatsoever. All of this we can imagine so the skeptic still has the space to remain skeptical should she decide to do so. However, as I said some conditions apply.

First, it is not clear if the imagined situation is consistent at all. A thought experiment of this kind could go astray. While philosophers are inclined to argue that they can imagine all sorts of things it might turn out that imagining is more demanding than they have initially thought. The famous 'brain in a vat' thought experiment has been challenged in this way (Thompson and Cosmelli, 2011). Thompson and Cosmelli have argued that once we start imagining the very details of how the brain in a vat functions it turns out that such brain would not be able to function without something like an operational body. So, for instance, in order to be alive such brain would need to have some sort of metabolism (the exchange of nutritive elements and oxygen). Also, simulating perception would require something like an operational eye (see e.g. A. Clark 2001) and so on. All of this would require some sort of body. However, to imagine a brain without the body was the sole purpose of this thought experiment. In the case of the thought experiment of our skeptic it remains to be seen if developmental psychology could play a role similar to the role that neurophysiology played in 'the brain in a vat' scenario. But, even if we cannot make such a strong case against our skeptic (as Thompson and Cosmelli made against theirs) we should still hold on to the insights about the development of human mind, social cognition, and 
language acquisition that we have gained from developmental psychology. These insights tell us that developmentally speaking there is no asymmetry between our self knowledge and knowledge of others and that our language emerges from preverbal communication. Now, this piling empirical evidence does tell us something about the inherently social nature of human minds and the origins of the meanings of mental concepts. Once we learn this lesson it is harder to take a sceptical attack seriously. Unless the skeptic gives us some additional reasons, not just imaginable situation, for doubting the existence of other minds we are safe to keep believing that they exist.

\section{References}

Avramides, A., (2001) Other Minds, London: Routledge

Baron-Cohen, S. (1989). „Are autistic children behaviorist? An examination of their mental-physical and appearance-reality distinctionis". Journal of autism and developmental disorders, 19, 579-600.

Baron-Cohen, S. (1995). Mindblidness: An essay on autism and theory of mind. Cambridge: Bradford/MIT Press.

Baron-Cohen, S., Leslie, A.M., \& Frith, U. (1985). „Does the autistic child have a „theory of mind"?", Cognition, 4, 37-46.

Bryson, S.E., Wainwright-Sharp, J. A., \& Smith, I.M. (1990). „Autism: A developmental spatial neglect syndrome?". In J Enns (Ed.), The development of attention: Research and Theory (pp. 405-427). North Holland: Elsevier.

Carruthers, P., (1996). "Autism as Mind-Blindness: an elaboration and partial defence". P. Carruthers \& (Eds.), P.K.Smith, Theories of theories of mind (pp. 257-273), Cambridge University Press.

Charman, T. (2003). „Why is joint attention a pivotal skill in autism?”. Philsophical Transactions of the Royal Society of London B, 358, 315-324.

Clark, A. (2001). Mindware: An Introduction to the Philosophy of Cognitive Science. New York: Oxford University Press.

Courchesne, E., Townsend, J., \& Akshoomoff, N. A. (1994). „Impairment in shifting attention in autistic and cerebellar patients". Behavioral Neuroscience, 108, 848-865.

Dawson, G., Lewy, A. (1989a). „Arousal, attention, and the socioemotional impairments of individuals with aurism". In G. Dawson (Ed.), Autism: Nature, diagnosis, and treatment (pp. 49-74). New York: Guilford Press.

Dawson, G., Lewy, A. (1989b). „Reciprocal subcortical-cortical influences in autism: The role of attentional mechanisms". In G. Dawson (Ed.), Autism: Nature, diagnosis, and treatment (pp. 144-173). New York: Guilford Press.

Dawson, G., Meltzoff, A., Osterling, J., \& Rinaldi, J. (1998). „Neurophychological correlates of early symptoms of autism". Child Development, 69, 1276-1285.

Dawson, G., Toth, K., Abbott, R., Osterling, J., Munson, J., Estes, A. \& Liaw, J. (2004). „Early social attention impairments in autism: Social orienting, joint attention and attention to distress". Developmental Psychology, 40, 271-283. 
Ellis, A.E., \& Oakes, L.M. (2006). „Infants flexibly use different dimensions to categorize objects". Developmental Psychology, 42, 1000-1011.

Hampshire, S., (1970). „The analogy of feeling”. in T.O. Buford (ed.), Essays on other minds (pp. 9-23). University of Illinois Press.

Hacker, P.M.S., (1972). Insight and illusion: Wittgenstein on philosophy and the metaphysics of experience, Clarendon Press

Hobson, P. (1993). Autism and the development of mind. Hove, UK: Lawrence Erlbaum Associates, Ltd.

Hyslop, A., (1995). Other Minds, Dordrecht/Boston/London, Kluwer Academic Publishers

Hurlbert, R.T., Happe, F., \& Frith, U.,(1994). „Sampling the form of inner experience in three adults with Asperger syndrome". Psychological Medicine, 24, 385-395.

Just, M. A., Cherkassky, V. L., Keller, T. A., \& Minshew, N. J. (2004). „Cortical activation and synchronization during sentence comprehension in highfunctioning autism: Evidence of underconnectivity". Brain, 127, 1811-1821.

Johnson, S. C. (2000). „The recognition of mentalistic agents in infancy”. Trends in Cognitive Sciences, 4, 22-28.

Kasari, C., Sigman, M., Mundy, P. \& Yirmiya, N. (1990). „Affective sharing in the context of joint attention interaction of normal, autistic and mentally retarded children". Journal of Autism and Developmental Disorders, 20, 87-100.

Kojen, L., (2009). Ogled iz filozofske psihologije, Čigoja Štampa

Kripke, S.A., (1982). Wittgenstein on Rules and Private Language, Blackwell

Leekam, S. R., \& Moore, C. (2001). „The development of attention and joint attention in children with autism". In J.A. Burack, T. Charman, N. Yirmiya, \& P.R. Zelazo (Eds.) The Development of autism: Perspectives from theory and research (pp. 105-31). New Jersey: Lawrence Erlbaum Associates.

Loveland, K., \& Landry, S. (1986). „Joint attention and language in autism and developmental language delay". Journal of Autism and Developmental Disorders, 16, 335-49.

Malcolm, N., (1958). „Knowledge of Other Minds”, Journal of Philosophy, vo1.55, 969-78.

Malcolm, N., (1959). Dreaming, London: Routledge

Markman, E., (1989). Categorization and naming in children. Cambridge, Mass.: The MIT Press.

Mill, J.S., (1872). An Examination of Sir William Hamilton's philosophy, (fourth edition), London: Longman, Green, Reader, and Dyer

Miller, Alexander and Crispin Wright, eds., (2002). Rule-Following and Meaning. Montreal and Kingston: McGill-Queens's University Press

Mundy, P. (1995). „Joint attention and socio-emotional approach behavior in children with autism". Development and Psychopathology, 7, 63-82.

Mundy, O., Sigman, M., Ungerer, J., \& Sherman, T. (1986). „Defining the social deficits in autism: The contribution of non-verbal communication measures". Journal of Child Psychology and Psychiatry and Allied Disciplines, 27, 657-669. 
Mundy, P. \& Crowson, M. (1997). „Joint attention and early social communication: Implications for research on interventions with autism". Journal of Autism and Developmental Disorders, 6, 653-676.

Mundy, O., \& Neal, R. (2001). „Neural plasticity, joint attention and a transactional social-orienting model of autism". In L. Glidden (Ed.), International review of research in mental retardation: Vol. 23. Autism (pp. 139-168). New York: Academic Press.

Panskepp, J. (1986). „The neurochemistry of behavior”. Annual Review of Psychology, 37, 77-107.

Paparella, T., D’Angiola., \& Kasari, C. (2001). „The emergence of joint attention skills, eye-contact, and positive affect in young children with autism". Poster presented at the 2001 meeting of the Society for Research in Child Development, Minneapolis, MN.

Paparella, T., \& Kasari, C. (2002). „The communicative quality of joint attention and requesting skills in young children with autism". Manuscript submitted for publication.

Plaisted, K. (2000). „Aspects of autism that theory of mind cannot explain”. In S. Baron-Cohen, H. Tager-Flusberg, \& D. Cohen (Eds.) Understanding other minds (pp. 224-250). New York: Oxford University Press.

Plaisted, K. (2001). „Reduced generalization in autism: An alternative to weak central coherence". In J.A. Burack, T. Charman, N. Yirmiya, \& P.R. Zelazo (Eds.) The Development of autism: Perspectives from theory and research (pp. 149-171). New Jersey: Lawrence Erlbaum Associates.

Russell, B., (1970). „Analogy”, in T.O. Buford (ed.), Essays on other minds (pp. 3-9). University of Illinois Press.

Shanker, S., (2013). Calm, alert, and learning, Pearson Canada Inc.

Tantam, D., (2009). Can the world afford autistic spectrum disorder? Nonverbal communication, asperger syndrome, and the interbrain, London: Jessica Kingsley Publishers.

Thompson, E., Cosmelli, D., (2011)."Brain in a vat or body in a world? Brainbound versus enactive views of experience", Philosophical topics, 39, 163-180.

Ter Hark, M.R.M., (1991), „The Development of Wittgenstein's Views about the Other Minds Problem", Synthese, 87, 227-53.

Walker-Andrews, A.S. (1997). „Infants' perception of expressive behaviors: Differentiation of multimodal information". Psychological Bulletin, 121, 437-456.

Wimmer, H. J. Perner, J. (1983). „Beliefs about beliefs: Representation and constraining function of wrong beliefs in young children's understanding of deception". Cognition 13 (1), 103-128.

Wittgenstein, L., (1953), Philosophical Investigations, Basil Blackwell. 